Sir,

\section{Bilateral self-enucleation of eyes}

Eye (2004) 18, 431-432. doi:10.1038/sj.eye.6700667

Self-enucleation of eyes in an extreme but fortunately rare form of self-harm. We present a case and review the literature.

\section{Case report}

A 48-year-old Caucasian male was brought to the Accident and Emergency Department with a history of self-gouging of both his eyes. Both his orbits were bandaged and there was very little ooze down over cheeks. His enucleated eyeballs, along with a long stump of optic nerve, were stored in a pot filled with normal saline (Figure 1 -both enucleated eyes). He was calm and apparently in no pain. The history was patchy and his relatives said that he indeed had a very troubled family life. There was no significant past ocular history. He was a known epileptic and had a recent epileptic attack, prior to the self-enucleation. His medication included topiramate and lamotrigine.

He was admitted to the ward for observation and possible repair of the sockets. In the ward, he was quiet and refused any medication. He refused a closer examination of his orbits. A psychiatric consult concluded that he was suffering from a postictal psychosis, which had led him to do such an act. He was under constant nursing supervision through out the night. The next morning the sockets were examined closely and it was decided to leave them to heal spontaneously. Chloramphenicol eye ointment was prescribed for the sockets. He was registered fully blind and referred to artificial eye centre for prosthesis. He remains under psychiatric care.

\section{Legendary background}

In the Greek play Oedipus Rex ${ }^{1}$ by Sophocles, the Theban King Oedipus unwittingly married his mother

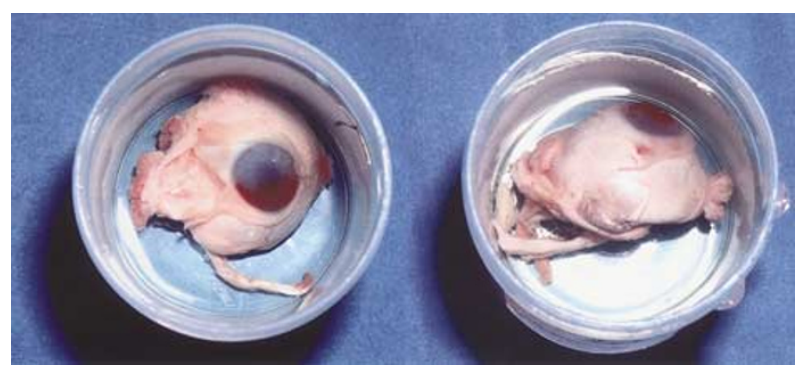

Figure 1 Both enucleated eyeballs. and killed his father. He then cleansed himself of the mortal sin by gouging his eyes out with his mother's golden brooches.

In the Bible: ${ }^{2}$ Matthew 5.29 quotes Jesus as saying 'And if thy right eye offend thee pluck it out, and cast it from thee: for it is profitable for thee that one of the thy members should perish, and not that thy whole body should be cast into hell'.

Marco Polo, ${ }^{3}$ in the 13th century, described a pious Baghdad carpenter who, after yielding to sinful thoughts about a young female customer, enucleated his right eye with his cobbler's awl.

Saint Triduan of Scotland, ${ }^{4}$ who on hearing that a prince was chiefly attracted by transcendent beauty of her eyes, enucleated her eyes to give to the prince.

Saint Lucia of Syracuse, ${ }^{5}$ who when fearing her vow for chastity, enucleated her own eyes and sent them to an admirer to stave off his advances.

In Norse mythology, ${ }^{6}$ Odin exchanged his eyes for the right to drink a single draught from the spring of Mimir, which offered wisdom and understanding.

\section{Comment}

The various forms of ocular self-mutilation include blunt trauma, penetrating injuries, and attempted and successful enculeation. Self-enucleation, also called Oedipism, is fortunately a rare form of extreme self-harm. There is no specific cause for people to enucleate their own eyes. The majority of the reported cases occur in those with psychotic illness, ${ }^{7}$ most commonly due to schizophrenia, drug-induced psychosis, manic phases of bipolar disorder, obsessive-compulsive neuroses, posttraumatic stress disorder, and depression. The psychotic patients frequently have delusions with religious and sexual content. ${ }^{8}$ Pain sensation has been noted to be considerably diminished in such patients, as shown in this case too. Organic illness ${ }^{7}$ that have been reported to stimulate self-mutilation of the eyes included delirium tremens, encephalitis, Lasche-Nyhan syndrome, Gilles de la Tourette's syndrome, Cornelia de Lange's syndrome, diabetes mellitus and epilepsy.

Completed digital self-enucleation is remarkable in that it tends to cause little haemorrhage, conserves ample conjunctiva for the lower fornix, and is followed by uneventful healing, whether the conjunctiva is sutured or not. The fitting of prostheses does not pose a serious problem in these cases. Management of patients following self-enucleation must involve a close cooperation between the ophthalmologist and the psychiatrist. Patients may not understand the implications of or may refuse treatment. Constant nursing supervision is necessary during in patient 
ophthalmic care, and lengthy in-patient psychiatric care may subsequently be needed. These patients are at high risk for further self-mutilation and precautions must be taken to prevent these.

\section{References}

1 Sophoecles(trans. Paul Roche): Oedipus Rex. Mentor: New York; 1958.

2 King James Bible. Matthew 5:29.

3 Polo M. Travels. Boni and Liverwright: New York, 1926: 9pp.

4 Forster J. The legend and shrine of saint Triduna. Br J Ophthalmol 1953: 37:763-765.

5 Koch FLP. Patron saints of the eyes:an outline. Am J Ophthalmol 1945: 28: 160-172.

6 Davidson HR. Gods and Myths of northern Europe. Penguin: Baltimore, 1964.

7 Aung T, Yap EY, Fam HB, Law NM, Oedipism. Aust NZ Ophthalmol 1996; 24(2): 153-157.

8 Witherspoon DC, Feist FW, Morris RE, Feist RM. Ocular self-mutilation. Ann Ophthalmol 1989; 21: 255-259.

BB Patil and N James

Department of Ophthalmology

Bradford Royal Infirmary

Duckworth lane

Bradford BD9 6RJ, UK

Correspondence: BB Patil

Tel: +44 7789777258

E-mail: bheemapatil@hotmail.com

Sir,

Orbital vasculitis following varicella. A case report Eye (2004) 18, 432-433. doi:10.1038/sj.eye.6700678

Chicken pox is a common childhood disease caused by the varicella zoster virus. Although most cases of varicella infection resolve without any sequelae, complications have been described. ${ }^{1,2}$ To our knowledge, this is the first case report of an orbital vasculitis following chicken pox infection in an immunocompetent patient.

\section{Case report}

A 7-year-old Filipino girl presented to the paediatric department with a 'swollen right eye', 6 days following chicken pox infection. On examination, she was systemically unwell and pyrexial. There was a right-sided axial proptosis with conjunctival chemosis and generalized restriction of extraocular movements. There was no relative afferent pupillary defect (RAPD) and her fundi looked healthy. She had neutrophilia and the Creactive protein (CRP) level was raised. An urgent contrast-enhanced CT scan showed inflammatory changes within the superior retro-orbital fat and opacification of the right maxillary sinus (Figure 1a and $b$ ). The other paranasal sinuses were clear. A diagnosis of bacterial orbital cellulitis was made and treatment with intravenous benzylpenicillin and flucloxacillin was commenced.

After 4 days, she was referred to the ophthalmic adnexal service for management as the proptosis had worsened (Figure 2a). The globe was displaced downwards and there was a mild right RAPD with mydriasis of the right pupil. Fundal examination remained unremarkable. Systemically, she was getting better with improvement in her neutrophilia and CRP levels.

An urgent repeat contrast-enhanced CT scan revealed prominent orbital blood vessels with surrounding extensive inflammatory changes. The maxillary sinusitis had improved with no evidence of an abscess or cavernous sinus thrombosis in the right orbit (Figure 1c and $\mathrm{d}$ ).

A noninfective inflammatory orbital disease affecting the orbital vasculature was suspected and high-dose oral prednisolone $(2 \mathrm{mg} / \mathrm{kg}$ ) was commenced under the cover of intravenous acyclovir $\left(250 \mathrm{mg} / \mathrm{m}^{2}\right.$ t.i.d.). There was a rapid improvement in her orbital

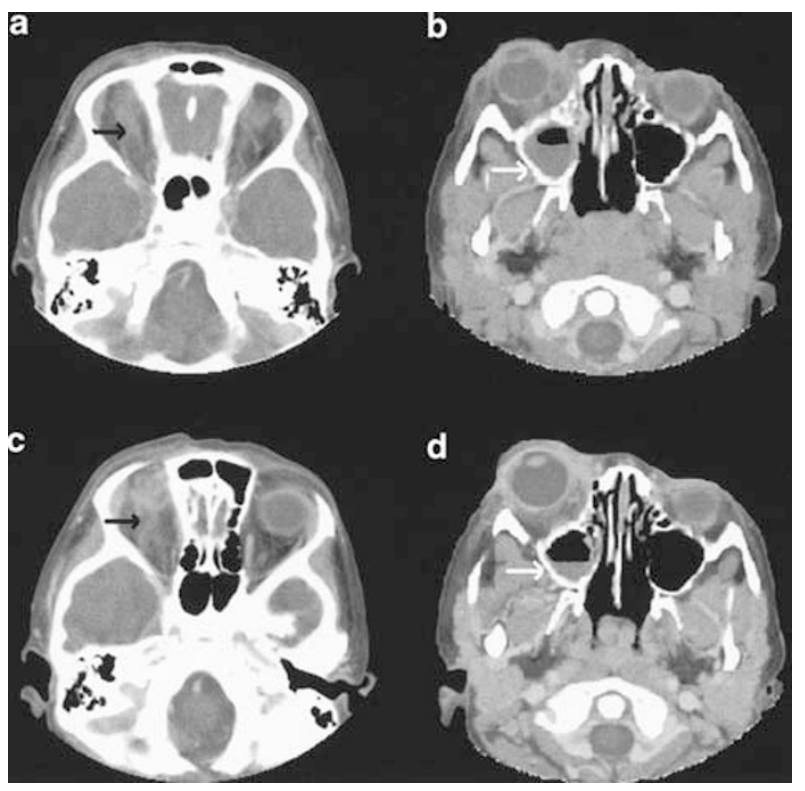

Figure 1 Contrast-enhanced CT scan of the orbits and paranasal sinuses on presentation $(a, b)$ and 4 days later $(c, d)$. Black arrows point to the dilated right superior ophthalmic vein. White arrows point to the opacified right maxillary sinus. 